\title{
Association between Growth Differentiation Factor 15 and Cardiovascular Risk in Patients with Type 2 Diabetes Mellitus
}

Mohamed M. El-Shafae ${ }^{a}$, Hesham A. Issa ${ }^{a}$, Abdel moneam A. Abdel moneam ${ }^{b}$, Walaa B. Abd El Hafez ${ }^{c}$, Enas S. Ahmed ${ }^{\mathrm{a}}$

${ }^{\mathrm{a}}$ Department of Clinical and Chemical Pathology, Faculty of Medicine, Benha University, Egypt. $\quad \mathrm{b}$ Department of internal medicine, Faculty of Medicine, Benha University, Egypt. ${ }^{\mathrm{c}}$ Department of Clinical and Chemical Pathology, Faculty of Medicine, Zagazig university, Egypt.

Correspondence to: Walaa B. Abd El Hafez, Department of Clinical and Chemical Pathology, Faculty of Medicine, Zagazig university, Egypt.

Email:

walaa.med87@hotmail.com

Received: 17 February, 2020

Accepted: 25 July, 2020

\begin{abstract}
:
Background: Growth Differentiation Factor 15 (GDF 15) is one of the transforming growth factor- $\beta$ (TGF- $\beta$ ) family, which is released from different cells under conditions of stress. Increased levels of GDF-15 are associated with cardiovascular diseases and are related to the progression and prognosis of the disease. Aim: the aim of the present study was to determine the correlation between serum GDF15 level and cardiovascular risk in patients with type2 DM using Framingham risk score (FRS). Subjects and methods: this study included three groups: control group $(n=20)$, prediabetic group $(n=30)$ and diabetic group $(n=30)$. The participants have been subjected to laboratory investigations including serum levels of GDF15, measured by enzyme linked immunosorbent assay (ELISA). FRS was calculated through using the 10-year CHD Risk Framingham Tables. Results: there was a statistically significant increase in serum GDF 15 in diabetic and prediabetic groups in comparison to the control group $(\mathrm{p}=0.006, \mathrm{p}=0.025)$ sequentially and serum GDF15 was significantly positively correlated with FRS in both the diabetic and prediabetic groups $(r=0.44, \mathrm{p}=0.015$ and $\mathrm{r}=$ 0.38, $\mathrm{p}=0.04)$ sequentially. Conclusion: Serum GDF15 level may be a useful clinical biomarker for predicting cardiovascular risk in patients with type2 DM.
\end{abstract}

Key words: Cardiovascular risk, Framingham Risk Score, GDF 15,type2 DM. 



\section{Introduction}

Diabetes mellitus (DM) is a global public health issue. It has affected about 387 million persons in the world in 2014.This number is expected to be increased to 592 million in the year of 2035. DM leads to many morbidity complications. One of which is the cardiovascular disease (CVD) that causes nearly $70 \%$ of deaths in diabetic patients [1].

Diabetes is characterized by high glucose level in due to either less insulin secretion from pancreas or developing insulin resistance in skeletal muscles. Diabetes can be categorized into many types; but the two major types of diabetes are type1 and type2 DM [2]. Type2 DM is responsible for about $90-95 \%$ of all cases of diabetes mellitus and is characterized by defects in insulin secretion and insulin resistance of varying degrees [3]. The risk of cardiovascular diseases is higher among type2 diabetic patients [4].

Different emerging biomarkers have been studied in cardiovascular conditions, growth differentiation factor-15(GDF-15) level was one of biomarkers that has taken a widespread interest as a predictor of cardiovascular disease [5]. GDF-15, also named mac $\neg$ rophage-inhibiting cytokine 1
(MIC-1), is a member of the trans-forming growth factor- $\beta$ (TGF- $\beta$ ) family [6]. It is released from many cell types e.g. macrophages, cardiomyocytes and adipocytes under stress [7]. GDF-15 increases during tissue injury and inflammatory conditions. Increased GDF-15 levels are associated with cardiovascular diseases such as hypertrophy, heart failure, atherosclerosis and endothelial dysfunction. Increased levels are also associated with the progression and prognosis of the disease [2]. Age, smoking, and environmental factors are other risk factors that may increase GDF15 level [2]. The aim of this study was to determine the correlation between serum growth differentiation factor 15 level and cardiovascular risk in patients with type 2 diabetes mellitus using Framingham risk score.

\section{Subjects and methods}

This is a case control study which included 80 participants recruited from the outpatient clinic and department of internal medicine of Benha University hospital during the period from May to November 2017. The laboratory investigations were done in the clinical and chemical pathology department, 
Benha University hospital. This study was approved by the ethical committee of Benha Faculty of Medicine, Benha University, Egypt. A written consent was obtained from all participants.

\section{Subjects:}

The subjects were divided into three groups: Control group (group I): which included 20 apparently healthy non smoker subjects.

Prediabetic group (groupII): which included 30 patients with impaired glucose tolerance. Diabetic group (group III): which included 30 patients with type 2 DM.

All subjects were above 18 years old. Patients with impaired glucose tolerance had fasting glucose $>110 \mathrm{mg} / \mathrm{dl} \&>126 \mathrm{mg} / \mathrm{dl}$ and 2-h postprandial glucose $\geq 140 \mathrm{mg} / \mathrm{dl} \&$ $>200 \mathrm{mg} / \mathrm{dl}$. Patients with type2 DM had fasting glucose $\geq 126 \mathrm{mg} / \mathrm{dl}$ or $2-\mathrm{h}$ postprandial glucose $\geq 200 \mathrm{mg} / \mathrm{dl}$. The subjects with malignancies, fatty liver, prior CVD and type1 DM were excluded. All participants were subjected to full history taking, physical examination including:(weight, height, BMI, systolic \& diastolic blood pressure), ECHO cardiography and laboratory investigations.

Methods : Ten milliliters of venous blood were collected from subjects who fasted for 10 hours, two milliliters were put on EDTA vacutainer tube for determination of HBA1C and the rest of collected sample was kept in plain test tubes, allowed to clot for 20 minutes at room temperature and centrifuged at $2000 \mathrm{x} \mathrm{g}$ for 15 minutes. Serum was separated in two aliquots and stored at $-20^{\circ} \mathrm{C}$ till analysis of GDF15, creatinine, urea, uric acid, lipid profile, fasting blood glucose (FBG), fasting Insulin. Two hours post prandial sample was collected in plain test tube, allowed to clot for 20 minutes at room temperature and centrifuged at $2000 \mathrm{x} \mathrm{g}$ for 15 minutes. Serum was collected and stored at $-20^{\circ} \mathrm{C}$ till analysis of $2 \mathrm{~h}$ postprandial glucose.

All the chemical investigations were performed on Biosystem Chemistry Analyzer (BTS-310, Spain). HbA1C was measured by NycoCard HBA1C which is a boronated affinity assay [8]. Fasting Insulin was measured by quantitative sandwich enzyme linked immunosorbent assay [9] using (Ylbiont (ELISA) kit, China, Catalog No.YLA1493HU) kit and performed on (BioTek $^{\mathrm{TM}} \quad$ ELx $800^{\mathrm{TM}} \quad$ Absorbance Microplate Readers). The homeostasis model assessment of insulin resistance (HOMA-IR) was calculated as follows: fasting insulin level $(\mu \mathrm{U} / \mathrm{ml}) \times$ fasting glucose level (mmol/l) / 22.5 [7]. HOMA $\beta$ index: was calculated as follows: fasting insulin level 
$(\mu \mathrm{U} / \mathrm{ml}) \times 20 /$ fasting glucose level $(\mathrm{mmol} / \mathrm{l})-$

3.5 [7]. FRS \% ( which was calculated by evaluating age, systolic blood pressure, need of treatment from hypertension, smoking status, presence of diabetes, levels of high density lipoprotein cholesterol (HDL-c) and total cholesterol through using the 10-year CHD ( Coronary Heart Disease) Risk Framingham [10] and GDF 15 was measured using a quantitative sandwich enzyme linked immunosorbent assay [11] using (ELISA) kit (OriGene Technologies, Rockville, MD; USA, Catalog No. EA100484) and performed on (BioTek ${ }^{\mathrm{TM}}$ ELx800 ${ }^{\mathrm{TM}}$ Absorbance Microplate Readers).

\section{Statistical analysis:}

The collected data were tabulated and analyzed using SPSS version 20 software (SPSS Inc, Chicago, ILL Company USA). Descriptive statistics were calculated for the data in the form of: mean and standard deviation $( \pm$ SD) for quantitative data and frequency and distribution for qualitative data. In the statistical comparison between the different groups, the significance of difference was tested using Student's t-test which is used to compare mean of two groups of quantitative data of parametric. ANOVA test ( $\mathrm{F}$ value) and is used to compare mean of more than two groups of quantitative data of parametric. The inter- group comparison of categorical data was performed by using chi square test (X2value). Correlation coefficient ( $r$ test) is used to find the relationship between variables. ROC curve is used to test validity of GDF15. $\mathrm{P}$ value $<0.05$ was considered statistically significant $(*)$ while $>0.05$ is statistically insignificant and $<0.01$ was considered highly significant $(* *)$ in all analyses.

\section{Results}

In this study, regarding the age, there was a statistically significant increase in diabetic group in comparison to control group ( $\mathrm{p} \leq$ $0.03)$.

Regarding the sex, diabetic group included $46.7 \%$ females and $53.3 \%$ males, prediabetic group included $43.3 \%$ females and $56.7 \%$ males. Control group included $(50 \%)$ females and (50\%) males (table 1). There was a statistically significant increase in LDL-c in diabetic group in comparison to prediabetic group and control group ( $\mathrm{p} \leq$ 0.001 and $\mathrm{p} \leq 0.001$ respectively) .

There was a statistically significant decrease in HDL-c in diabetic group in comparison to prediabetic group and control group ( $\mathrm{p} \leq$ 0.001 and $\mathrm{p} \leq 0.001$ respectively). There was a statistically significant increase in total cholesterol, triglycerides in diabetic group 
and prediabetic group in comparison to control group $(\mathrm{p} \leq 0.001, \mathrm{p} \leq 0.001, \mathrm{p} \leq$ 0.001 and $p \leq 0.001$ respectively). There was a statistically significant increase in LDL-c in prediabetic group in comparison to control group $(\mathrm{p} \leq 0.001)$. There was a statistically significant decrease in HDL-c in prediabetic group in comparison to control group ( $\mathrm{p} \leq$ 0.001) (figure 1). There was a statistically significant increase in FBS, P.P glucose, HbA1C, insulin and HOMA-IR in diabetic group in comparison to prediabetic group and control group $(\mathrm{p} \leq 0.001, \mathrm{p} \leq 0.001, \mathrm{p} \leq$ $0.001, p \leq 0.002$ and $p \leq 0.001)$ respectively and there was a statistically significant increase in FBS, P.P glucose, HbA1C and HOMA IR in prediabetic group in comparison to control group $(\mathrm{p} \leq 0.001, \mathrm{p} \leq$ $0.001, p \leq 0.001$ and $p \leq 0.001)$ respectively. There was a statistically significant increase in FRS and GDF15 in diabetic group in comparison to control group $(\mathrm{p} \leq 0.001$ and $\mathrm{p}=0.006$ ) respectively. There was a statistically significant increase in FRS and GDF15 in prediabetic group in comparison to control group $(\mathrm{p} \leq 0.005$ and $\mathrm{p}=0.025)$ respectively. There was a statistically significant decrease in Homa $\beta$ index in diabetic group and prediabetic group in comparison to control group ( $\mathrm{p} \leq 0.001$ and $\mathrm{p} \leq 0.001$ ) respectively (table 2 ). There was a statistically significant increase in GDF15 in diabetic group and prediabetic group in comparison to control group $(\mathrm{p}=0.006$ and $\mathrm{p}$ $=0.025)$ respectively (table 3 ). There was a statistically significant positive correlation in diabetic group between GDF15 and age ( $\mathrm{r}=$ $0.29, \mathrm{p}=0.01)$, total cholesterol $(\mathrm{r}=0.4, \mathrm{p}=$ $0.03)$, triglycerides $(\mathrm{r}=0.39, \mathrm{p}=0.03) \mathrm{LDL}-\mathrm{c}$ $(\mathrm{r}=0.29, \mathrm{p}=0.01), \mathrm{FBS}(\mathrm{r}=0.45, \mathrm{p}=0.01)$, P.P glucose $(r=0.51, p=0.003), \mathrm{HbA} 1 \mathrm{C}$ $(\mathrm{r}=0.37, \mathrm{p}=0.04)$, HOMA IR $(\mathrm{r}=0.36, \mathrm{p}=$ $0.04)$ and FRS $(r=0.44, p=0.015)$ (table 4). There was a statistically significant positive correlation in prediabetic group between GDF15 and age $(\mathrm{r}=0.45, \mathrm{p}=0.01)$, total cholesterol $(\mathrm{r}=0.39, \mathrm{p}=0.02)$, triglycerides $(\mathrm{r}=0.38, \mathrm{p}=0.03)$, LDL-c $(\mathrm{r}=0.28, \mathrm{p}=0.01)$, FBS $(r=0.43, p=0.015)$, P.P glucose $(r=$ $0.45, \mathrm{p}=0.011), \operatorname{HbA1C}(\mathrm{r}=0.36, \mathrm{p}=0.04)$, FRS $(r=0.38, p=0.04)$ and SBP $(r=0.38, p=$ 0.03) (table 5). ROC curve was performed to test validity of GDF15 in prediabetes group. It has a sensitivity of $86.7 \%$ and specificity of $55 \%$ in predicting the cardiovascular risk in prediabetic subjects with area under the curve $(\mathrm{AUC})=0.744$ and cut off value $=$ $414.07 \mathrm{pg} / \mathrm{ml}$ as shown in fig. ( 2 ). ROC curve was performed to test validity of GDF 15 in diabetic group. It has a sensitivity of $86.6 \%$ and specificity of $52 \%$ in predicting the cardiovascular risk in diabetic patients with $($ AUC $)=0.692$ and cut off value $=$ $468.3 \mathrm{pg} / \mathrm{ml}$ as shown in table ( 6 ). 
Table (1): Comparison between the studied groups according to : Age, sex, Wt, Ht, BMI, SBP, DBP:

\begin{tabular}{|c|c|c|c|c|c|c|c|}
\hline & $\begin{array}{l}\text { Diabetic } \\
\text { group } \\
(\mathbf{n}=30)\end{array}$ & $\begin{array}{l}\text { Prediabetic } \\
\text { group } \\
(\mathbf{n}=30)\end{array}$ & $\begin{array}{l}\text { Control } \\
\text { group } \\
(\mathbf{n}=\mathbf{2 0})\end{array}$ & $\begin{array}{l}\text { F } \\
\text { test }\end{array}$ & $\begin{array}{l}\text { Diabetic\# } \\
\text { prediabetic }\end{array}$ & $\begin{array}{l}\text { P value } \\
\text { Diabetic\# } \\
\text { control }\end{array}$ & $\begin{array}{l}\text { Prediabetic\# } \\
\text { Control }\end{array}$ \\
\hline $\begin{array}{l}\text { Age (yr) } \\
\text { Sex }\end{array}$ & $57.23 \pm 7.87$ & $53.87 \pm 8.74$ & $51.9 \pm 9.86$ & 2.42 & 0.12 & $0.039 *$ & 0.46 \\
\hline $\begin{array}{l}\text { Male } \\
\text { Female }\end{array}$ & $\begin{array}{l}16(53.3) \\
14(46.7)\end{array}$ & $\begin{array}{l}17(56.7) \\
13(43.3)\end{array}$ & $\begin{array}{l}10(50.0) \\
10(50.0)\end{array}$ & $\begin{array}{l}X^{2}= \\
0.22\end{array}$ & 0.80 & 0.82 & 0.64 \\
\hline Wt (kg) & $97.48 \pm 7.23$ & $96.98 \pm 8.07$ & $78.05 \pm 6.96$ & 49.18 & 0.80 & $0.001 * *$ & $0.001 * *$ \\
\hline Ht $(\mathbf{c m})$ & $174.77 \pm 7.29$ & $174.93 \pm 6.68$ & $171.15 \pm 5.16$ & 2.37 & 0.93 & 0.06 & 0.37 \\
\hline BMI $\left(\mathbf{k g} / \mathbf{m}^{2}\right)$ & $32.06 \pm 3.40$ & $31.8 \pm 3.62$ & $26.63 \pm 2.01$ & 20.52 & 0.78 & $0.001 * *$ & $0.001 * *$ \\
\hline SBP(mmHg) & $132.9 \pm 12.82$ & $134.1 \pm 12.51$ & $126.55 \pm 6.27$ & 2.86 & 0.72 & $0.046^{*}$ & $0.016^{*}$ \\
\hline DBP(mmHg) & $81.67 \pm 8.74$ & $85.67 \pm 7.96$ & $79.55 \pm 5.38$ & 4.13 & 0.07 & 0.34 & $0.004 * *$ \\
\hline
\end{tabular}

Table (2): Comparison between the studied groups according to: FBG, P.P glucose, HbA1c, Insulin, Homa IR, Homa $\beta$ index, Framingham risk score (FRS).

\begin{tabular}{|c|c|c|c|c|c|c|c|}
\hline & \multirow[b]{2}{*}{$\begin{array}{c}\text { Diabetic } \\
\text { Group }\end{array}$} & \multirow[b]{2}{*}{$\begin{array}{c}\text { Pre-diabetic } \\
\text { group }\end{array}$} & \multirow[b]{2}{*}{$\begin{array}{l}\text { Control } \\
\text { Group }\end{array}$} & \multirow[b]{2}{*}{ F test } & \multicolumn{2}{|c|}{$P$ value } & \multirow[b]{2}{*}{$\begin{array}{l}\text { Pre. \# } \\
\text { Control }\end{array}$} \\
\hline & & & & & $\begin{array}{c}\text { diabetic\# } \\
\text { prediabetic }\end{array}$ & $\begin{array}{r}\text { diabetic\# } \\
\text { control }\end{array}$ & \\
\hline $\begin{array}{l}\text { FBG } \\
(\mathrm{mg} / \mathrm{dl})\end{array}$ & $139.25 \pm 5.74$ & $117.41 \pm 4.22$ & $86.86 \pm 6.44$ & 561.24 & $0.001 * *$ & $0.001 * *$ & $0.001^{* *}$ \\
\hline $\begin{array}{l}\text { PP gl. } \\
\text { (mg/dl) }\end{array}$ & $298.56 \pm 71.6$ & $159.82 \pm 16.12$ & $101.99 \pm 6.1$ & 130.1 & $0.001 * *$ & $0.001 * *$ & $0.001^{* *}$ \\
\hline $\begin{array}{l}\mathrm{HbA1c} \\
(\%)\end{array}$ & $8.61 \pm 2.14$ & $6.0 \pm 0.51$ & $5.38 \pm 0.44$ & 42.42 & $0.001 * *$ & $0.001 * *$ & $0.001^{* *}$ \\
\hline $\begin{array}{l}\text { Insulin } \\
(\mu \mathrm{U} / \mathrm{ml})\end{array}$ & $20.06 \pm 4.47$ & $15.31 \pm 3.37$ & $16.07 \pm 3.7$ & 12.43 & $0.002^{* *}$ & $0.002 * *$ & 0.46 \\
\hline Homa-IR & $6.65 \pm 1.57$ & $4.39 \pm 1.0$ & $3.42 \pm 0.85$ & 48.08 & $0.001 * *$ & $0.001 * *$ & $0.001 * *$ \\
\hline $\begin{array}{c}\text { Homa- } \beta \\
\%\end{array}$ & $93.5 \pm 21.8$ & $104.26 \pm 23.93$ & $266.58 \pm 84.73$ & 97.77 & 0.07 & $0.001 * *$ & $0.001 * *$ \\
\hline FRS $\%$ & $13.2 \pm 2.57$ & $11.67 \pm 3.96$ & $8.3 \pm 3.95$ & 11.92 & 0.08 & $0.001 * *$ & $0.005^{* *}$ \\
\hline
\end{tabular}

Table (3): Comparison between studied groups aacording to GDF 15 level:

\begin{tabular}{lccccccc}
\hline $\begin{array}{l}\text { GDF15 } \\
(\mathbf{p g} / \mathbf{m l})\end{array}$ & $\begin{array}{c}\text { Diabetic group } \\
(\mathbf{n}=\mathbf{3 0})\end{array}$ & $\begin{array}{c}\text { Prediabetic } \\
\text { group }(\mathbf{n = 3 0})\end{array}$ & $\begin{array}{c}\text { Control group } \\
(\mathbf{n = 2 0})\end{array}$ & $\mathbf{F}$ test & \multicolumn{3}{c}{ P value } \\
& & & & $\begin{array}{l}\text { Diabetic\# } \\
\text { prediabetic }\end{array}$ & $\begin{array}{l}\text { Diabetic\# } \\
\text { control }\end{array}$ & \multicolumn{1}{c}{$\begin{array}{l}\text { Prediabetic\# } \\
\text { control }\end{array}$} \\
\hline median & 652.35 & 430.6 & 222.4 & $\mathrm{X} 2=$ & 0.54 & $0.006^{* *}$ & $0.025^{*}$ \\
$(\mathbf{I Q R})$ & $(370-2002)$ & $(180-1450.3)$ & $(150-1150)$ & 8.27 & & & \\
\hline
\end{tabular}


Benha medical journal vol. 37, issue 3, 2020

Table (4): Correlation between GDF15 and other variables among diabetic group:

\begin{tabular}{|c|c|c|}
\hline \multirow[t]{2}{*}{ Diabetes group } & \multicolumn{2}{|c|}{ GDF15 (pg/ml) } \\
\hline & $r$ test & $P$ value \\
\hline$\overline{\text { Age (years) }}$ & 0.29 & $0.01 *$ \\
\hline BMI $\left(\mathrm{kg} / \mathrm{m}^{2}\right)$ & 0.21 & 0.26 \\
\hline SBP (mmHg) & 0.235 & 0.2 \\
\hline DBP (mmHg) & -0.008 & 0.97 \\
\hline Urea (mg/dl) & 0.33 & 0.08 \\
\hline Cr. (mg/dl) & -0.24 & 0.20 \\
\hline Uric acid (mg/dl) & 0.09 & 0.63 \\
\hline $\mathrm{TC}(\mathrm{mg} / \mathrm{dl})$ & 0.403 & $0.03^{*}$ \\
\hline $\mathrm{TG}(\mathrm{mg} / \mathrm{dl})$ & 0.391 & $0.03 *$ \\
\hline HDL-c (mg/dl) & -0.153 & 0.4 \\
\hline LDL-c (mg/dl) & 0.299 & $0.01 *$ \\
\hline FBG (mg/dl) & 0.457 & $0.01 *$ \\
\hline P.P gl. (mg/dl) & 0.516 & $0.003 *$ \\
\hline $\mathrm{Hb}$ A1c (\%) & 0.370 & $0.04 *$ \\
\hline Homa IR & 0.366 & $0.04 *$ \\
\hline Homa- $\beta$ \% & -0.06 & 0.77 \\
\hline FRS \% & 0.440 & $0.015^{*}$ \\
\hline Hs CRP (mg/l) & 0.217 & 0.25 \\
\hline
\end{tabular}

Table (5): Correlation between GDF15 and other variables among prediabetic group:

\begin{tabular}{lcc}
\hline \multicolumn{1}{c}{ Pre-diabetes group } & \multicolumn{2}{c}{ GDF 15 (pg/ml) } \\
& r test & P value \\
\hline Age (years) & 0.45 & $0.01^{*}$ \\
BMI(kg/m²) & 0.17 & 0.3 \\
SBP(mmHg) & 0.38 & $0.03^{*}$ \\
DBP(mmHg) & 0.45 & 0.12 \\
Urea(mg/dl) & -0.33 & 0.07 \\
Cr.(mg/dl) & 0.28 & 0.13 \\
Uric acid (mg/dl) & 0.25 & 0.18 \\
TC (mg/dl) & 0.397 & $0.02^{*}$ \\
TG (mg/dl) & 0.388 & $0.03^{*}$ \\
HDL-c (mg/dl) & 0.45 & 0.12 \\
LDL-c (mg/dl) & 0.289 & $0.01^{*}$ \\
FBG (mg/dl) & 0.437 & $0.015^{*}$ \\
P.P gl. (mg/dl) & 0.455 & $0.011^{*}$ \\
Hb A1c (\%) & 0.369 & $0.04^{*}$ \\
Homa IR & 0.331 & 0.07 \\
Homa- $\beta$ \% & -0.11 & 0.56 \\
FRS\% & 0.380 & $0.04^{*}$ \\
Hs Crp (mg/dl) & 0.20 & 0.28 \\
\hline
\end{tabular}


Table (6): Performance of GDF15 as a predictor of cardiovascular risk in diabetic patients.

\begin{tabular}{lcccc}
\hline \multicolumn{1}{c}{ GDF15 } & $\begin{array}{c}\text { Diabetic group } \\
\mathbf{( 3 0 )}\end{array}$ & $\begin{array}{c}\text { Control group } \\
\mathbf{( 2 0 )}\end{array}$ & $\mathrm{X}^{2}$ & P value \\
$\geq 468.3 \mathrm{pg} / \mathrm{ml}$ & $27(90 \%)$ & $7(35 \%)$ & 9.92 & $0.002^{* *}$ \\
$<468.3 \mathrm{pg} / \mathrm{ml}$ & $3(10 \%)$ & $13(65 \%)$ & & \\
AUC & & 0.692 & & \\
Cutoff point & & 468.3 & & \\
(pg/ml) & & 86.6 & & \\
Sensitivity \% & & 52.0 & \\
Specificity \% & & 75.7 & \\
PPV\% & 64.8 & \\
NPV\% & 80.0 & \\
Accuracy\% & & & \\
\hline
\end{tabular}

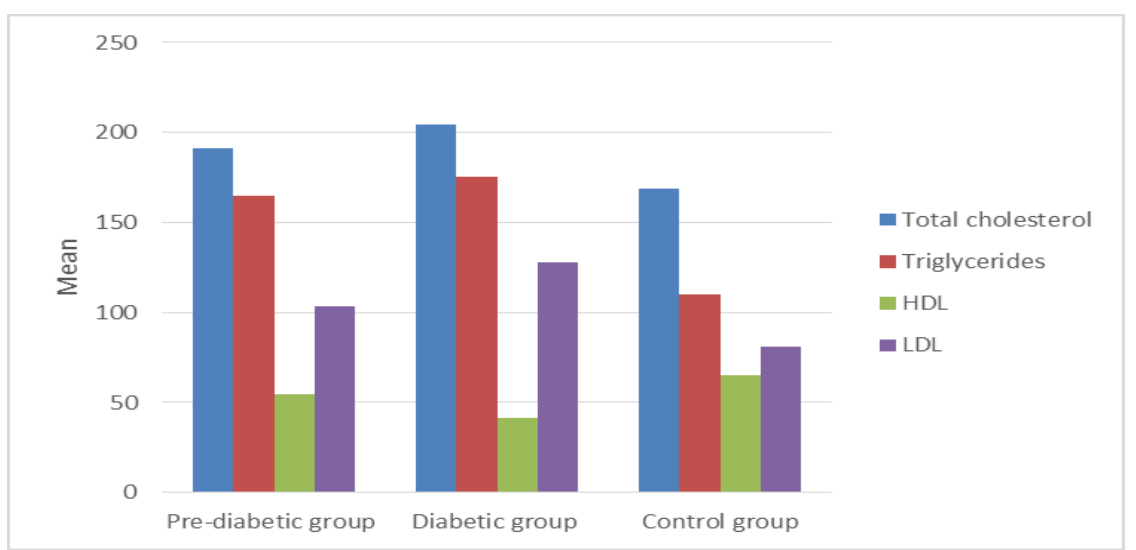

Figure (1): Comparison between the studied groups according to total cholesterol (mg/dl), triglycerides (mg/dl), HDL-c (mg/dl), LDL-c (mg/dl).

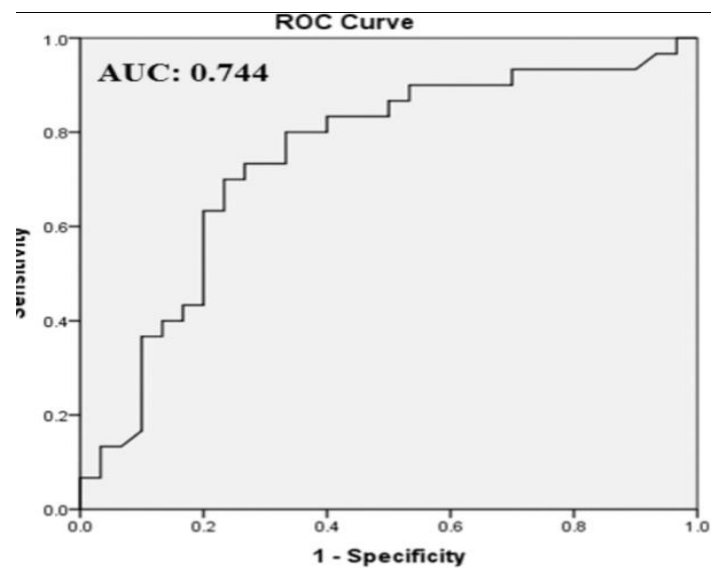

Figure (2): ROC curve of GDF 15(pg/ml) for prediction of cardiovascular risk in prediabetic patients. 


\section{Discussion}

Growth differentiation factor-15 (GDF-15) is one of the transforming growth factor- $\beta$ cytokine family that is produced in response to oxidative stress and inflammation by multiple cell types, including macrophages, adipocytes and cardiovascular cells [12]. Circulating concentration of serum GDF-15 levels is associated with increased risk of cardiovascular diseases [13]. In diabetic patients there are many factors that induce the development of cardiovascular diseases. These factors include the impairment of glucose metabolism, dyslipidemia, adipose tissue dysfunction and excessive oxidative stress [14].

All these factors are able to induce endothelial dysfunction, leading to cardiac remodeling and hypertrophy, worse vascular integrity and cardiac function [15]. Among all these factors the oxidative stress is the most important which causes the release of GDF 15 from adipocytes and cardiovascular cells [16]. The Framingham Risk Score is a gender-specific algorithm used to estimate the 10-year cardiovascular risk of individuals. It can predict the risk of developing cardiovascular diseases and also can indicate who is the most likely to benefit from prevention [17].
In the current study, as shown in figure ( 1 ) total cholesterol and triglycerides levels were higher in the diabetic group than in the control group $(p=0.046, \quad p=0.001$ respectively). The total cholesterol was also significantly increased in Schindler et al. [18], Hong et al. [19] and in Shin et al. [7] studies $(\mathrm{p}=0.01, \mathrm{p}<0.001$ and $\mathrm{p}=0.035$ respectively) in diabetic group in comparison to control group.

In Hong et al. [19] study, there was significant increase in triglycerides among diabetic group in comparison to control group ( $\mathrm{p}=0.017)$. In the present study, there were significant increase in total cholesterol, triglycerides and LDL-c in prediabetic group in comparison to control group $(p<0.001$ in each) and these results are in agreement with results of Hong et al. [19], Stentz et al. [20] and Zheng et al. [21].

In the current research, there was a significant decrease in HDL-c in diabetic group in comparison to prediabetic group $(p=0.001)$ compared to results of Hong et al. [22] in which the HDL-c was significantly decreased in diabetes group in comparison to prediabetes group $(\mathrm{p}=0.012)$. The lipid profile is expected to be increased in diabetic and prediabetic patients as there is increased 
incidence of metabolic syndrome which is characterized by abdominal obesity, insulin resistance, dyslipidemia and hypertension [17]. In the present study there was significant increase in $\mathrm{HbAlC}$ in diabetic group in comparison to prediabetic and control groups $(\mathrm{p}=0.001)$ as shown in table ( 2 ). This is consistent with results of Navarro et al. [23], Schindler et al. [18] and Shin et al. [7].

HbA1C in these studies was significantly increased in diabetic patients in comparison to non diabetic persons ( $\mathrm{p}<0.001$ in all). Poor control of diabetes lead to increase in HbA1C level which is also affected by many factors. Factors that influence $\mathrm{HbA1C}$ are anemia, haemoglobinopathies, liver diseases, ingestion of alcohol, vitamin $\mathrm{C}$ and vitamin E., etc. [18]. In this study, there was significant increase in insulin in diabetic group in comparison to prediabetic and control group $(\mathrm{p}=0.002)$ as shown in table ( 2 ) and this is in agreement with Hong et al. [19] result.

In Hong et al. [19] study, there was significant increase in insulin in diabetic group in comparison to control group $(\mathrm{p}<0.001)$. In type $2 \mathrm{DM}$, there is increase in the demand of insulin by the pancreas, and balance of insulin and blood sugar are affected [22]. Type2 DM is preceded by a long period of insulin resistance. $\beta$ cells are trying to compensate for insulin resistance by adequately increasing insulin production [24]. In the current study, the calculated HOMA-IR level was elevated in the prediabetic group (4.39 \pm 1.0$)$, and it was the highest in the diabetic group $(6.65 \pm 1.57)$. HOMA-IR levels in the diabetic group and prediabetic group showed the presence of IR. There is significant increase in HOMA IR in diabetic and prediabetic groups in comparison to control group $(\mathrm{p} \leq 0.001)$ and there is significant increase in HOMA IR in diabetic in comparison prediabetic group $(\mathrm{p}=0.001)$ as shown in table ( 2 ) and this result is in agreement with results of Hong et al. [22] and Shin et al. [7] $(\mathrm{p}<0.001$ in both studies).

In subjects with genetic predisposition, the combination of excess caloric intake and relatively decreased physical activity, with the likely resulted obesity, can induce a condition of resistance to the insulin action. Moreover, there is accumulation of fat in skeletal muscles and liver which decreases the cell response to insulin and thus increases the insulin resistance [24]. In the current study, there was significant decrease in Homa $\beta$ index $(p=0.001)$ in the diabetic group and prediabetic group in comparison to the control group and this result is in 
agreement with results of Shin et al. [7] and Hong et al. [22]. In both studies the Homa $\beta$ index was significantly decreased in diabetic patients ( $\mathrm{p}<0.001$ in both studies). Prolonged exposure to high glucose, elevated free fatty acids levels, or a combination of both lead to $\beta$-cell dysfunction [24].

According to the present study, there was a statistically significant increase in GDF 15 in diabetic and prediabetic groups in comparison to the control group ( $<<0.006$ ) as shown in table ( 3 ) and this result is in agreement with results of DominguezRodriguez et al. [26], Hong et al. [22], Shin et al. [7] and Adela et al. [27]. The impairment of glucose metabolism, dyslipidemia, adipose tissue dysfunction and excessive oxidative stress are factors that induce endothelial dysfunction in diabetic and prediabetic patients [14].

These factors worsen vascular integrity and cardiac function and lead to release of GDF 15 from adipocytes and cardiovascular cells [15]. In the present study, there is statistically significant increase in FRS in diabetic and prediabetic groups in comparison to control group ( $\mathrm{p} \leq 0.001)$.

In the present study, significant positive correlations were evident between GDF15 level and age $(\mathrm{p}=0.03)$, total cholesterol $(\mathrm{p}=0.03)$, FBS $(\mathrm{p}=0.01), \mathrm{Hb}$ A1c $(\mathrm{p}=0.04)$, Homa IR ( $\mathrm{p}=0.04)$ and FRS $(\mathrm{p}=0.015)$ in diabetic group as shown in table (4). In Hong et al. [22] study, GDF15 had significant positive correlation with age $(\mathrm{p}<0.001)$, FBS $(\mathrm{P}<0.001)$ and HOMA-IR $(\mathrm{P}<0.001)$ and it was negatively correlated with HDL-c $(\mathrm{p}=0.011)$.

In Shin et al. [7] study, GDF 15 was correlated with FBS $(\mathrm{p}<0.001)$, HbA1C $(\mathrm{p}=0.001)$, HOMA-IR $(\mathrm{p}=0.02)$ and FRS $(p<0.001)$. In the present study, there was a significant positive correlation between the GDF 15 level and age ( $\mathrm{p}=0.02)$, SBP $(\mathrm{p}=0.03), \quad$ total cholesterol $\quad(\mathrm{p}=0.02)$, triglycerides $(\mathrm{p}=0.03)$, LDL-c $(\mathrm{p}=0.01), \mathrm{FBS}$ $(\mathrm{p}=0.015)$, P.P glucose $(\mathrm{p}=0.011), \mathrm{Hb} \mathrm{A} 1 \mathrm{c}$ $(\mathrm{p}=0.04)$ and FRS $(\mathrm{p}=0.04)$ in prediabetic group as shown in table ( 5 ).

ROC curve was performed to test validity of GDF15. It has a sensitivity of $86.7 \%$ and specificity of $55 \%$ in predicting the cardiovascular risk in prediabetic subjects (figure 2) with area under the curve $($ AUC $)=$ 0.744 and cut off value $=414.07 \mathrm{pg} / \mathrm{ml}$. It has a sensitivity of $86.6 \%$ and specificity of $52 \%$ in predicting the cardiovascular risk in diabetic patients table (6) with (AUC) $=0.69$ and cut off value $=468.3 \mathrm{pg} / \mathrm{ml}$. Studies of Anand et al. [16], Bonaca et al. [28] and Wollert et al. [29] have reported that there 
are associations between GDF15 levels and various types of CVD. The GDF15 level was reported to be a prognostic marker of heart failure [16]. The level of GDF15 can be a useful predictive biomarker of diabetic cardiomyopathy in patients with type2 DM [25]. It may be used as a useful biomarker for mortality in patients with non-STelevation myocardial infarction [29]. The recurrent adverse effects after the development of acute coronary syndrome were found to be associated with increased levels of GDF15 [28].

\section{Conclusion}

Through using of Framingham Risk Score, we noticed an association between serum GDF15 level and cardiovascular risk factors in type 2 DM patients. This suggests that GDF15 serum level can be used as a useful predictive biomarker for incidence of cardiovascular diseases in patients with type2 DM.

Conflicts of interest: There are no conflicts of interest

\section{References}

1.Wan E, Fong D, Fung C, Lam C (2016): Incidence and predictors for cardiovascular disease in Chinese patients with type 2 diabetes mellitus - a populationbased retrospective cohort study. Journal of Diabetes and Its Complications; 30: 444-450.
2.Adela R and Banerjee S (2015): GDF-15 as a Target and Biomarker for Diabetes and Cardiovascular Diseases: A Translational Prospective. Journal of Diabetes Research; Article ID 490842, 14 pages.

3.Ipadeoal A and Adeleye J (2016): THE metabolic syndrome and accurate cardiovascular risk prediction in persons with type 2 diabetes mellitus. Diabetes \& Metabolic Syndrome: Clinical Research \& Reviews; $10: 7-12$

4.Shah A, Langenberg C, Rapsomaniki E, Denaxas S, Pujades-Rodriguez M, Gale C, et al. (2015): Type 2 diabetes and incidence of cardiovascular diseases: a cohort study in 1.9 million people. Lancet Diabetes Endocrinol; 3:105-113.

5.Sari K, Ede H, Gencer Z, et al. (2015): The Correlation of Serum Growth Differentiation Factor15 Level in Patients with Obstructive Sleep Apnea. BioMed Research International; Article ID 807683, 5 pages.

6.Zheng H, Wu Y, Guo T, Liu F, Xu Y, Cai S (2020): Hypoxia Induces Growth Differentiation Factor15 to Promote the Metastasis of Colorectal Cancer via PERK-eIF2 $\alpha$ Signaling. BioMed Research International; Article ID 5958272, 12 pages.

7.Shin M, Kim J, Kang Y, Kim M, Joung K, Lee J, et al. (2016): Association between Growth Differentiation Factor 15 (GDF15) and Cardiovascular Risk in Patients with Newly Diagnosed Type 2 Diabetes Mellitus. J.Korean.Med.Sci.; 31(9):1413-1418.

8.Holzl W, Weykamp C, Jepsson J, Miedema K, Barr J, Goodall I, et al., (2004): IFCC reference system for the measurement of haemoglobin A1C in human blood and the national standardization schemes in the 
Benha medical journal vol. 37, issue 3, 2020

United States, Japan and Sweden: a method comparative study. Clin Chem;50(1):166-174.

9.Lindstrom T, Hedman C and Arnquist H. (2002): Use of a novel double-antibody technique to describe the pharmacokinetics of rapid-acting insulin analogs. Diabetes Care 25:1049-1054.

10.Agostino D, Vasan R, Pencina M, Wolf P, Cobain M, Massaro J, et al. (2008): General Cardiovascular Risk Profile for Use in Primary Care. The Framingham Heart Study. Circulation; (117): 743753.

11.Ago $\mathrm{T}$ and Sadoshima $\mathrm{J}$ (2006):GDF15, a cardioprotective TGF-beta superfamily protein.Circ Res 98 (3): 294-297.

12.Dostalova I, Roubicek T, Bartlova M, Mraz M, Lacinova Z, Haluzikova D, et al. (2009): Increased serum concentrations of macrophage inhibitory cytokine- 1 in patients with obesity and type 2 diabetes mellitus: the influence of very low calorie diet. European Journal of Endocrinology; 161:397-404.

13.Daniels L, Clopton P, Laughlin G, Maisel A, Barrett-Connor E (2011): Growth-differentiation factor-15 is a robust, independent predictor of 11-year mortality risk in community-dwelling older adults: the Rancho Bernardo Study. Circulation; 123:2101-10.

14.Stinkens R, Goossens G, Jocken J, Blaak E (2015): Targeting fatty acid metabolism to improve glucose metabolism. Obesity Reviews; 16, 715-757.

15.Beatty A, Ku I, Bibbins-Domingo K, Christenson R, Defilippi C, Ganz P, et al. (2015): Traditional Risk Factors Versus Biomarkers for Prediction of Secondary Events in Patients With Stable Coronary Heart Disease: From the Heart and Soul Study. Journal of the American Heart Association; 4 (7).
16.Anand I, Kempf T, Rector T, Tapken H, Allhoff T, Jantzen F, et al. (2010): Serial measurement of growth differentiation factor-15 in heart failure: relation to disease severity and prognosis in the Valsartan Heart Failure Trial. Circulation; 122(14): 1387-95.

17.Joseph J, Babu M, Prasanth G, Naidu K (2016): assessment of cardiovascular risk in patients without known cardiovascular disease in general medicine department of bmch and rc. World journal of pharmacy and pharmaceutical SCIENCES; Volume 5, Issue 6, 1819-1825.

18.Schindler K, Vila G, Hoppichler F, Lechleitner M, Luger A, Anderwald C, et al. (2012): The Impact of Type 2 Diabetes on Circulating Adipokines in Patients with Metabolic Syndrome. Obesity Facts; 5:270-276.

19.Hong JH, Choi YK, Min BK, Park K, Seong K, Lee I, et al. (2015): Relationship between hepcidin and GDF15 in anemic patients with type 2 diabetes without overt renal impairment. Diabetes Research and Clinical Practice; 109(1): 64-70.

20.Stentz F, Brewer A, Wan J, Garber C, Daniels B, Sands C, et al. (2016): Remission of pre-diabetes to normal glucose tolerance in obese adults with high protein versus high carbohydrate diet: randomized control trial. BMJ open diabetes research and care; 4:e000258

21.Zheng F, Yan L, Yang Z, Zhong B, Xie W ( 2018): $\mathrm{HbA1c}$, diabetes and cognitive decline: The English longitudinal study of aging. Diabetologia; 61:839 848.

22.Hong J, Chung H, Park H, Joung K, Lee J, Jung J, et al. (2014): GDF15 Is a Novel Biomarker for 
Impaired Fasting Glucose. Diabetes \& Metabolism Journal; 38:472-479.

23.Navarro.J, Mora.C, Maciea.M, Garciea J (2003): Inflammatory Parameters Are Independently Associated With Urinary Albumin in Type 2 Diabetes Mellitus. American Journal of Kidney Diseases; Vol 42, No.1: pp 53-61.

24.Islam R (2017): Association between SocioDemographic Factors and Blood Sugar Levels in Type 2 Diabetes Mellitus Patients in Bangladesh. Journal of Diabetes Mellitus; 7, 151-159.

25.Ceriello.A and Enrico.M (2004): Is Oxidative Stress the Pathogenic Mechanism Underlying Insulin Resistance, Diabetes, and Cardiovascular Disease? The Common Soil Hypothesis Revisited. Arteriosclerosis, Thrombosis, and Vascular Biology;24:816-823.

26.Dominguez-Rodriguez A, Abreu-Gonzalez P, Avanzas P (2014): Usefulness of growth differentiation factor-15 levels to predict diabetic cardiomyopathy in asymptomatic patients with type 2 diabetes mellitus. Am J Cardiol; 114: 890-894.

27.Adela R, Mohammed S, Kanwal A, Vishwakarma G, Reddy P, Banerjee S (2016): Elevated levels of GDF-15 is associated with increased angiotensin II in hypertensive patients with Type 2 diabetes. Personalized Medicine; 13(4), 325-336.

28.Bonaca M, Morrow D, Braunwald E, Cannon C, Jiang S, Breher S, et al. (2010): Growth differentiation factor-15 and risk of recurrent events in patients stabilized after acute coronary syndrome: observations from PROVE IT-TIMI 22. Arteriosclerosis, Thrombosis and Vascular Biology; 31:203-210.

29.Wollert K, Kempf T, Peter T, Olofsson S, James S, Johnston S, et al. (2007): Prognostic value of growth differentiation factor-15 in patients with non-ST elevation acute coronary syndrome. Circulation; 115:962-971.

To cite this article: Mohamed M. El-Shafae, Hesham A. Issa, Abdel moneam A. bdel moneam, Walaa B. Abd El Hafez, Enas S. Ahmed. Association between growth differentiation factor 15 and cardiovascular risk in patients with type 2 diabetes mellitus, BMFJ 2020; 37(3): 653-666, DOI:10.21608/bmfj.2020.24147.1216 
Original article 